\title{
Optic nerve sheath diameter, intracranial pressure and acute mountain sickness on Mount Everest: a longitudinal cohort study
}

\author{
A I Sutherland, ${ }^{1}$ D S Morris, ${ }^{2}$ C G Owen, ${ }^{3}$ A J Bron, ${ }^{4}$ R C Roach ${ }^{5}$
}

${ }^{1}$ Nuffield Department of

Surgery, John Radcliffe Hospital, University of Oxford, UK; ${ }^{2}$ Royal Victoria Infirmary, Queen Victoria Rd, Newcastle upon Tyne, UK; ${ }^{3}$ Division of Community Health Sciences, St George's,

University of London, UK;

${ }^{4}$ Nuffield Laboratory of Ophthalmology, University of Oxford, UK; ${ }^{5}$ Research Division, Altitude Research Center,

University of Colorado Denver Health Sciences Center, Mail Stop F-524, P0 Box 6508, Aurora, Colorado, USA

Correspondence to: Dr A Sutherland, Wellcome Research Training Fellow, Nuffield Department of Surgery, Level 6, John Radcliffe Hospital, Oxford OX3 9DU, UK; aisutherland@mac.com

Accepted 5 December 2007 Published Online First 8 January 2006

\section{ABSTRACT}

Objective: To investigate the association of optic nerve sheath diameter (ONSD), as a correlate of intracranial pressure (ICP), with acute mountain sickness (AMS).

Design: Longitudinal cohort study of mountaineers from sea level to $6400 \mathrm{~m}$.

Setting: Mount Everest (North side).

Participants: 13 mountaineers (10 men, 3 women; aged 23-52 years) on a British expedition to climb Mount Everest.

Interventions: ONSD was measured ultrasonically, $3 \mathrm{~mm}$ behind the globe using B scans recorded with an OTI-Scan 3D scanner (Ophthalmic Technologies, Canada). Serial binocular scans were recorded at sea level, and 2000, 3700, 5200 and $6400 \mathrm{~m}$. All ONSDs were measured by a blinded observer.

Main outcome measures: ONSD, AMS score lusing the Lake Louise scoring system), heart rate, and oxygen saturation levels.

Results: All results were analysed by regression analysis with adjustment. ONSD was positively associated with increasing altitude above sea level $(0.10 \mathrm{~mm}$ increase in ONSD per $1000 \mathrm{~m}, 95 \% \mathrm{Cl} 0.05$ to $0.14 \mathrm{~mm}$ ) and AMS score $(0.12 \mathrm{~mm}$ per score, $95 \% \mathrm{Cl} 0.06$ to $0.18 \mathrm{~mm})$; further associations were found with resting heart rate ( $0.29 \mathrm{~mm}$ per 20 beats/min, $95 \% \mathrm{Cl} 0.17$ to $0.41 \mathrm{~mm}$ ) and oxygen saturations $(0.20 \mathrm{~mm}$ per $10 \%$ decrease, $95 \%$ Cl 0.11 to $0.29 \mathrm{~mm}$ ).

Conclusions: ONSD increases at high altitude, and this increase is associated with more severe symptoms of AMS. Given the linkage between ONSD and ICP, these results strongly suggest that intracranial pressure plays an important role in the pathophysiology of AMS.

Despite the fact that acute mountain sickness (AMS) has been recognised as a specific condition since the early 20th century, the mechanisms underlying its development remain unclear. ${ }^{1}$ AMS occurs in about half of lowlanders after rapid ascent to altitudes $>2500 \mathrm{~m},{ }^{2}$ and is characterised by headache, nausea, vomiting and fatigue. Owing to the similarity between the symptoms of AMS and those of raised intracranial pressure (ICP), it has long been suggested that the symptoms of AMS may be caused by raised ICP. ${ }^{3}$ The only certain way to determine ICP is by direct measurement of intraventricular or subdural pressure. Studies using these direct measures in both small and large animals have shown that ICP increases significantly at higher simulated altitudes. ${ }^{4-6}$ Direct measurement of intraventricular or subdural pressure is clearly not practical or ethical in an ambulatory healthy human population. An alternative is to measure cerebrospinal fluid pressures (CSFp), usually by lumbar puncture, which correlates strongly with ICP. ${ }^{7}$ The evidence for raised CSFp in people with AMS is limited. Two studies at simulated high altitude showed raised CSFp in people with moderate to severe AMS, ${ }^{3}{ }^{8}$ but another, more recent, study showed no difference in CSFp in those with mild to moderate AMS. ${ }^{9}$ No study to date has satisfactorily measured ICP and AMS under field conditions of hypobaric hypoxia.

This study set out to explore the association between ICP and AMS at increasing altitudes in humans, using a new, non-invasive ultrasound method to measure optic nerve sheath diameter (ONSD). This technique has been described recently as a safe and reliable method to assess ICP. ${ }^{10}{ }^{11}$ The optic nerve sheath is continuous with the dura mater, and CSF usually communicates freely between the intracranial space and the optic nerve. ${ }^{12}$ Using B-scan ultrasound of the eye, it is possible to determine the ONSD, which has been shown to have a linear correlation with ICP. ${ }^{11}{ }^{13-15}$ This technique has been used successfully to identify raised ICP in children with hydrocephalus, ${ }^{16}$ and in patients with head injuries in the emergency room ${ }^{17} 18$ and the intensive care unit. ${ }^{19}$ The measure has been shown to have good interobserver and intra-observer repeatability, ${ }^{20}$ and portable equipment is available that allows measurements to be taken in remote settings, including at high altitude. The aim of this study was to measure ONSD at different altitudes above sea level, as a correlate of ICP, in a cohort of mountaineers attempting to climb Mount Everest.

\section{METHODS}

The experimental protocols were approved by the Oxford Tropical Research Ethics Committee (Ref: 015-06 "Investigation of Intracranial Pressure at High Altitude"). Informed consent was obtained from all participants.

\section{Study subjects}

A cohort study of 13 mountaineers (all white Europeans; 10 men, 3 women; aged mean age 34.3 (SD 8.2) years, range 23 to 53 ) recruited from a British expedition climbing the north side of Mount Everest (March-June 2006). Seven subjects (4 men, 3 women) cycled from the Dead Sea (400 metres below sea level) to Everest base camp (EBC; 5200 metres; fig 1) between December 2005 and March 2006, before their ascent of Everest. The remaining subjects ascended to EBC by road, 10 days after arrival in Kathmandu, Nepal (from 


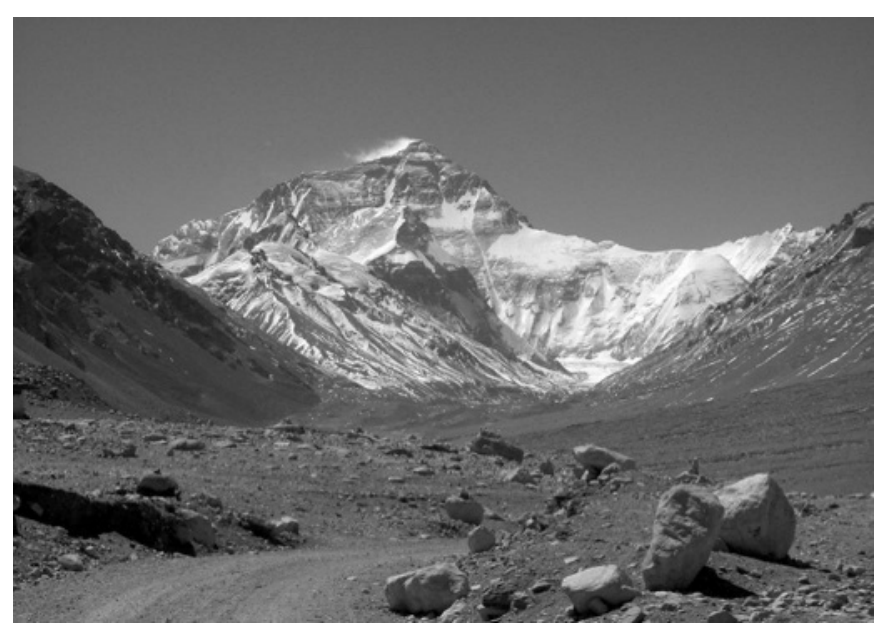

Figure 1 In total, 13 subjects were studied during their ascent of the north side of Mount Everest, seen here from the road to Everest base camp, $5200 \mathrm{~m}$.

1600 to 5200 metres). The ascent profile of both groups to EBC is shown in fig 2.

\section{Optic nerve sheath diameter measurements}

Serial ultrasound B-scans of both eyes were made using a portable OTI-Scan 3D B-Scan with a $12 \mathrm{MHz}$ probe (Ophthalmic Technologies, Canada). Scans were recorded at 2000 m, 3700 m, 5200 m and 6400 m (by AIS, except AIS's own scans, which were recorded by CGO). Scans at sea level were recorded 3 months after return to the UK. Each scan was recorded 12-24 hours after arrival at each altitude up to $5200 \mathrm{~m}$. After arrival at EBC, subjects followed individual altitude profiles, and scans at $6400 \mathrm{~m}$ were made within 72 hours of arrival at this altitude.

Subjects were examined in the supine position. The probe was placed lightly over each closed eyelid using an aqueous contact gel. Eye structures were imaged in order to align the optic nerve directly opposite the probe. This was achieved by ensuring that the posterior aspect of the lens was visible in the scan. A continuous recording of the scan was made (typically

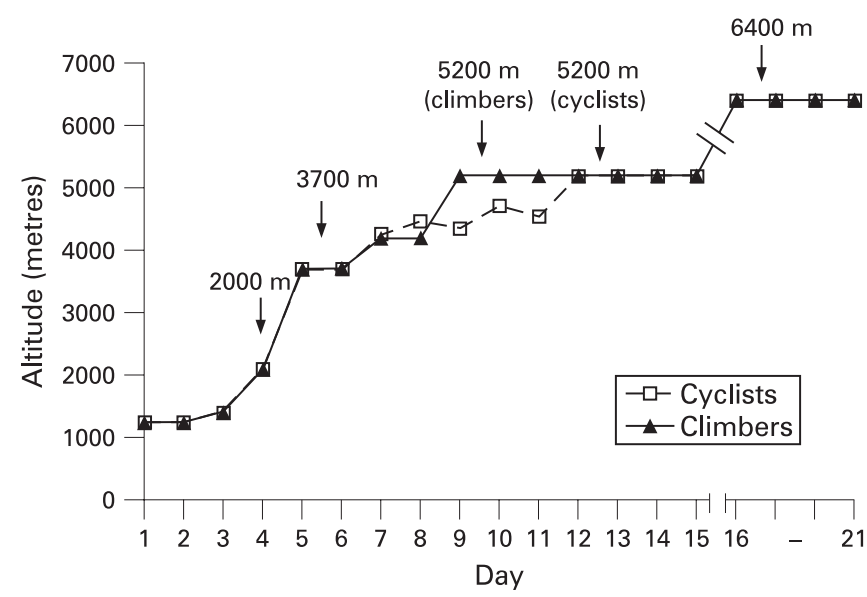

Figure 2 Altitude ascent profile of climbers and cyclists from Kathmandu (1300 m) to Everest base camp (EBC 5200 m). Data collection points are indicated with arrows. Subjects followed individual ascent profiles between EBC $(5200 \mathrm{~m})$ and the final data collection point $(6400 \mathrm{~m})$.
30 seconds) and all the scans were analysed on return to the UK by an observer (DSM) blinded to any identifying information.

ONSD was measured $3 \mathrm{~mm}$ behind the globe in each eye, and the average of three measurements was recorded. A distance of $3 \mathrm{~mm}$ was used because changes in ONSD with ICP are greatest at this level. ${ }^{10}$ The quality of each scan was graded by the blinded observer, who documented the posterior lens as present or absent and graded definition of the optic nerve sheath border from 1 to 3, (1, very good; 2, good; 3, poor).

\section{Other measures}

At each altitude, AMS was assessed using the Lake Louise subjective scoring system, ${ }^{21}$ and resting heart rate and oxygen saturations (Nonin Onynx Pulse Oximeter; Nonin Medical Inc, Plymouth, Minnesota, USA) were also recorded. No restrictions were placed on the medications that subjects were taking, and a record of these was made. A self reported assessment of height was also obtained.

\section{Statistical analysis}

The association of ONSD (mean of three readings taken per scan) with (1) altitude above sea level, (2) AMS score, (3) resting heart rate and (4) oxygen saturations were examined using generalised estimating equations in Stata (Stata/SE V.9.2 for Windows, StataCorp LP, College Station, Texas, USA). This regression analysis (using the XTGEE command) allows for repeated measures in the same person. ONSD appeared to be normally distributed. Analyses were adjusted a priori for age, gender, right and left eyes, assessment of scan quality and whether the ocular lens was visible in the scan or not, and for three subjects who had returned to $6400 \mathrm{~m}$ after an earlier climb. Associations 1-4 were examined by categories of the exposure variable, for altitude (sea level, $2000 \mathrm{~m}, 3700 \mathrm{~m}$, $5200 \mathrm{~m}$ and $6400 \mathrm{~m}$ ), AMS score (with scores $\geqslant 4$ combined) and quintiles of resting heart rate and oxygen saturations. The assumption of linearity appeared appropriate throughout, and the exposures were also fitted as continuous variables for altitude (change in ONSD per $1000 \mathrm{~m}$ ), heart rate (per 20 beats/ min, as sample SD 18 beats/min), oxygen saturations (per 10\% increase, as sample SD 11\%), and as a linear term for AMS score.

Adjustment for exposures 1-4 in the same regression model was examined to see if the associations observed were altered. However, findings were interpreted cautiously because these variables are strongly correlated (absolute values for sample correlation coefficients ranged from 0.38 to 0.71 ), which can lead to unstable estimates of effect.

Between-eye differences in ONSD with altitude were examined, but showed no appreciable association and are not reported further. Logistic regression analyses (adjusted for sex) were also used to examine whether measurements of ONSD at

Table 1 Summary of the measures taken at each altitude

\begin{tabular}{llllll}
\hline $\begin{array}{l}\text { Altitude } \\
(\mathbf{m})\end{array}$ & $\begin{array}{l}\text { Subjects, } \\
\text { (men) }\end{array}$ & $\begin{array}{l}\text { ONSD (mm) } \\
\text { mean (SD) }\end{array}$ & $\begin{array}{l}\text { AMS score, } \\
\text { mean (SD) }\end{array}$ & $\begin{array}{l}\text { Resting HR } \\
\text { (beats/min) } \\
\text { mean (SD) }\end{array}$ & $\begin{array}{l}\text { 0xygen } \\
\text { saturations (\%), } \\
\text { mean (SD) }\end{array}$ \\
\hline 0 & $13(10)$ & $4.69(0.46)$ & $0(0)$ & $57(5)$ & $97.0(0)$ \\
2000 & $13(10)$ & $4.89(0.68)$ & $0.6(1.4)$ & $70(11)$ & $95.4(1.1)$ \\
3700 & $12(9)$ & $4.91(0.48)$ & $1.6(1.1)$ & $77(11)$ & $87.6(2.5)$ \\
5200 & $13(10)$ & $5.20(0.66)$ & $2.8(1.3)$ & $89(20)$ & $74.8(8.3)$ \\
6400 & $10(9)$ & $5.31(0.75)$ & $2.6(1.9)$ & $96(10)$ & $71.3(6.4)$
\end{tabular}

AMS, acute mountain sickness; HR, heart rate; ICP, intracranial pressure; ONSD, optic nerve sheath diameter.

*ONSD mean of right and left eyes for the sample. 
lower altitudes (2000 $\mathrm{m}$ and $3700 \mathrm{~m}$ ), predict AMS scores at $5200 \mathrm{~m}$ (presence of AMS being defined as a score $\geqslant 3$ ).

\section{RESULTS}

Table 1 summarises the measures taken at each altitude. ONSD (expressed as the mean of right and left eyes) and mean resting heart rate both increased at higher altitudes. AMS scores were greater with increasing altitude, reaching a maximum at 5200 metres. Oxygen saturations fell with increasing altitude.

ONSD measurements were recorded on all 13 subjects up to $5200 \mathrm{~m}$, with the exception of $3700 \mathrm{~m}$, for which one subject was unavailable. ONSD measurements were recorded on 10 subjects $(9 \mathrm{men})$ at $6400 \mathrm{~m}$. Although there were only three women in the study, ONSD was on average $1 \mathrm{~mm}$ smaller ( $95 \%$ CI 0.7 to $1.3 \mathrm{~mm}, \mathrm{p}<0.001$ ) in women compared with men. This is likely to reflect the gender difference in stature; on average, men were $20 \mathrm{~cm}(95 \%$ CI 12 to $27 \mathrm{~cm}, \mathrm{p}<0.001)$ taller than women. In adjusted regression analyses, an increase of 1000 metres in altitude was associated with a $0.1 \mathrm{~mm}$ increase in ONSD (95\% CI 0.05 to $0.14 \mathrm{~mm}$ ) (table 2, fig 3a). Time at altitude before measurement (from 24 to 72 hours at $6400 \mathrm{~m}$ ), use of medications (carbonic anhydrase inhibitors and/or analgesics), and whether subjects climbed to the summit of Everest (six subjects, including AIS and CGO), had no appreciable effect on the association between altitude and ONSD (all $\mathrm{p}>0.2$ ). A positive association with ONSD was observed for Lake Louise AMS scores (table 2, figs $3 b$ and 4). At $5200 \mathrm{~m}$, three subjects had an average ONSD >6 mm. One of these subjects developed high-altitude pulmonary oedema, and another developed high-altitude cerebral oedema on further ascent to $6400 \mathrm{~m}$ (ophthalmic ultrasound images from this subject are shown in fig 5).

A strong association with heart rate was also found, showing an ONSD that was $0.3 \mathrm{~mm}$ wider for each 20 beats $/ \mathrm{min}$ increase in resting heart rate ( $95 \%$ CI 0.2 to 0.4 , table 2, fig 3c). This corresponded with an inverse association between ONSD and oxygen saturations (table 2, fig 3d) that appeared to plateau at levels $<80 \%$; there was insufficient power to formally test this apparent deviation from linearity. The effects of altitude,
AMS, and oxygen saturations on ONSD were attenuated to the null in a model containing all primary exposures. This was not surprising considering the strong associations between variables. However, the effect of resting heart rate remained statistically significant in this model, with a $0.2-\mathrm{mm}$ wider ONSD $(95 \% \mathrm{CI}$ 0.04 to $0.41, \mathrm{p}=0.018$ ) for each 20 beats/min increase in heart rate.

Although a $0.1-\mathrm{mm}$ increase in ONSD at $2000 \mathrm{~m}$ and $3700 \mathrm{~m}$ increased the risk of an AMS score of $\geqslant 3$ at $5200 \mathrm{~m}$, the $95 \%$ CI for these results are wide and compatible with no effect (1.2, 95\% CI 0.9 to 1.6 ; $1.7,0.9$ to 3.0 , respectively).

\section{DISCUSSION}

We were able to perform external B-scan ultrasound of the eye, allowing measurement of ONSD in a cohort of mountaineers attempting to climb Mount Everest. We have shown for the first time that ONSD shows a graded increase with altitude, and that this increase may begin at altitudes as low as $2000 \mathrm{~m}$. ONSD and AMS symptoms were also strongly associated, showing a marked dose response, suggesting that ONSD not only increases on ascent to progressively higher altitudes, but that this increase may accompany the development of AMS. Previous studies have showed that ONSD is strongly associated with ICP, and therefore the results support the hypothesis that AMS may be a symptom of raised ICP.

In interpreting our results, it is important to understand the relationship between ONSD and ICP. The use of B-scan ultrasound for ONSD measurement was first reported by Hansen and Helmke, ${ }^{10}$ a development that substantially advanced the clinical utility of ONSD measurements for noninvasive ICP assessment. These authors showed in 12 subjects that serial B-scan ultrasound measurements of ONSD were responsive to changes in CSFp during intrathecal infusion tests. ${ }^{11}$ Although CSFp is not a direct measure of ICP, a recent study has suggested that it is a very reliable measure of ICP. ${ }^{7}$ A near-linear correlation was found between CSF pressure and ONSD $(r=0.86)$, although this relationship was not as good at extreme pressures. ${ }^{11}$ Although the linear relationship was maintained in all 12 people in that study, the degree of change
Figure 3 Change in mean optic nerve sheath diameter (ONSD) with (a) altitude (metres), (b) as a correlate of intracranial pressure (ICP), to acute mountain sickness (AMS) (measured by Lake Louise Scoring system), (c) heart rate (beats/min), and (d) oxygen saturations (\%). Vertical error bars refer to $95 \%$ confidence intervals in ONSD.
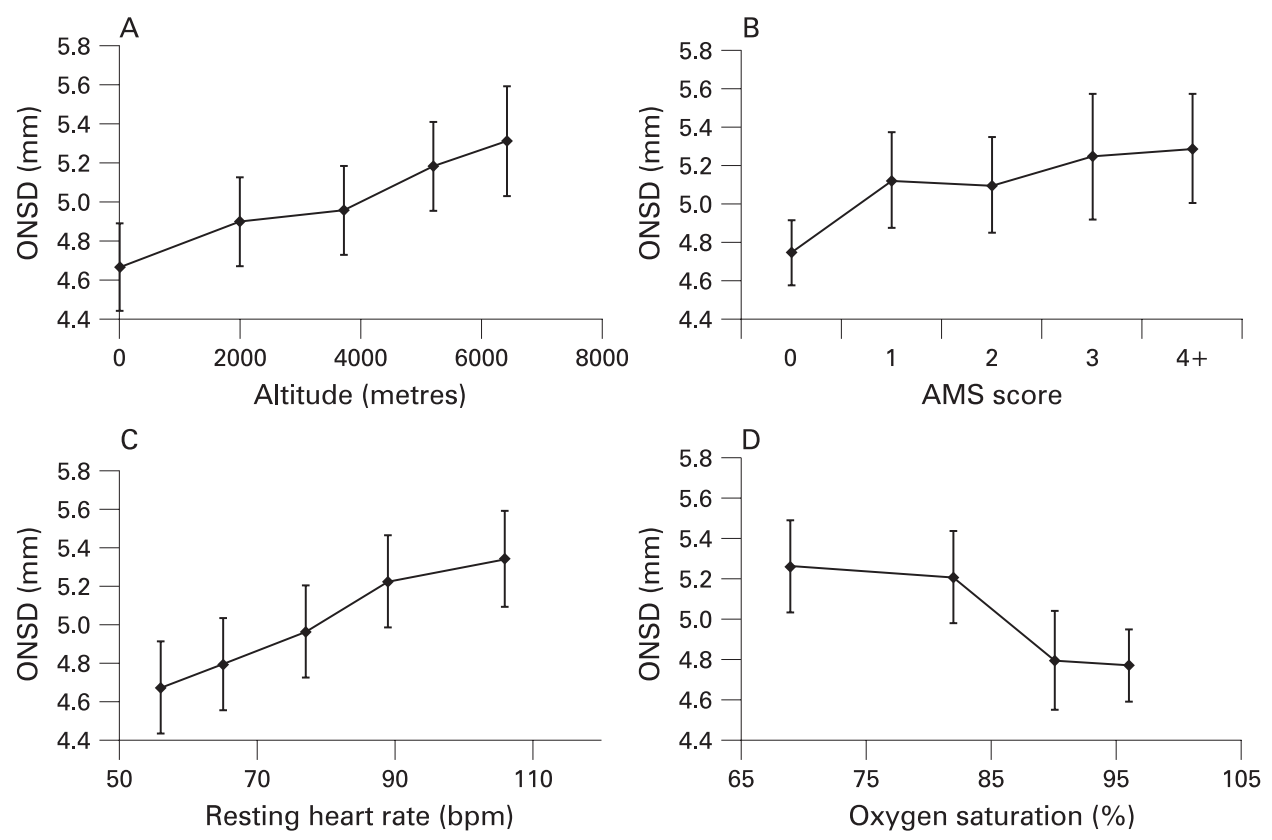


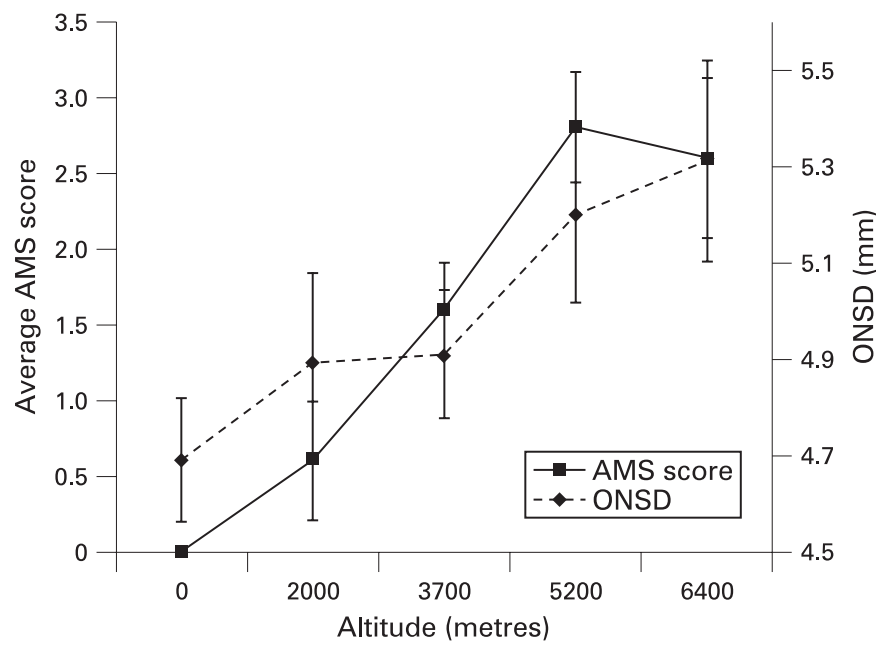

Figure 4 Average optic nerve sheath diameter (ONSD) and acute mountain sickness (AMS; scored using the Lake Louise Scoring system) at each data collection point (vertical error bars represent $+/$ - standard error of the mean).

in ONSD per mmHg CSFp varied greatly between them $(0.019$ to $0.071 \mathrm{~mm} / \mathrm{mmHg}$ ). The correlation of ONSD with intraventricular ICP monitoring has only been examined in a small number of studies, ${ }^{14}{ }^{15} 22$ and because of the invasive nature of measuring ICP, this has only been carried out in a limited number of heterogeneous patients. However, such studies support the findings of Hansen and Helmke ${ }^{11}$ that changes in ONSD allow relative, but not absolute, changes in ICP to be gauged.

One of the major strengths of our study was the longitudinal nature of the design, allowing within-person repeated measures of ONSD, at altitudes ranging from sea level to $6400 \mathrm{~m}$. The analytical approach took account of ONSD variations both within and across individuals. Hence, the observed associations are not diluted by variations in ONSD across different people, as each person acts as their own control. This improves the statistical power of the associations seen with ONSD. A blinded observer was used for all ONSD measurements to remove observer bias, and we believe that the quality of our measurements of ONSD was further enhanced by a continuous recording, using MPEG files, of the ocular scans performed, which allowed the observer to select the maximum ONSD. The use of a high-resolution probe $(12 \mathrm{MHz}$ versus $10 \mathrm{MHz}$ used in
Table 2 Change in ONSD by Altitude, AMS score, heart rate, and oxygen saturations

\begin{tabular}{|c|c|c|}
\hline Altitude & Mean ONSD* $(95 \%$ CI) & p Value \\
\hline 0 & $4.67(4.45$ to 4.89$)$ & Ref \\
\hline 2000000 & $4.90(4.67$ to 5.13$)$ & 0.12 \\
\hline 3700700 & 4.95 (4.72 to 5.18$)$ & 0.06 \\
\hline 5200200 & 5.18 (4.96 to 5.41$)$ & $<0.001$ \\
\hline 6400400 & 5.31 (5.03 to 5.60$)$ & $<0.001$ \\
\hline Per 1000 metre & $0.10(0.05$ to 0.14$)$ & $<0.001$ \\
\hline \multicolumn{3}{|l|}{ AMS score } \\
\hline 0 & 4.75 (4.58 to 4.91$)$ & Ref \\
\hline 1 & 5.12 (4.87 to 5.37$)$ & $<0.01$ \\
\hline 2 & $5.10(4.85$ to 5.35$)$ & 0.02 \\
\hline 3 & 5.24 (4.92 to 5.57$)$ & $<0.01$ \\
\hline $4+$ & 5.29 (5.01 to 5.56$)$ & 0.001 \\
\hline Per unit AMS score & $0.12(0.06$ to 0.18$)$ & $<0.001$ \\
\hline \multicolumn{3}{|l|}{ Resting heart rate (beats $/ \mathrm{min}) \dagger$} \\
\hline 1st quintile $(56,47$ to 59$)$ & 4.67 (4.43 to 4.91$)$ & Ref \\
\hline 2nd quintile $(65,60$ to 71$)$ & $4.79(4.56$ to 5.03$)$ & 0.47 \\
\hline 3rd quintile $(77,74$ to 81$)$ & $4.96(4.72$ to 5.20$)$ & 0.10 \\
\hline 4th quintile $(89,82$ to 95$)$ & $5.22(4.98$ to 5.47$)$ & $<0.01$ \\
\hline 5th quintile $(106,96$ to 130$)$ & $5.34(5.10$ to 5.59$)$ & $<0.001$ \\
\hline Per 20 beats $/ \mathrm{min}$ & $0.29(0.17$ to 0.41$)$ & $<0.001$ \\
\hline \multicolumn{3}{|l|}{ Oxygen saturation $(\%) \dagger$} \\
\hline 1st quintile $(67,56$ to 74$)$ & $5.23(4.98$ to 5.48$)$ & Ref \\
\hline 2nd quintile $(79,75$ to 82$)$ & $5.25(5.01$ to 5.50$)$ & 0.90 \\
\hline 3rd quintile $(86,83$ to 89$)$ & $4.97(4.74$ to 5.21$)$ & 0.13 \\
\hline 4th quintile $(94,90$ to 95$)$ & $4.88(4.59$ to 5.16$)$ & 0.06 \\
\hline 5th quintile $(97,96$ to 97$)$ & $4.70(4.51$ to 4.90$)$ & 0.001 \\
\hline Per $10 \%$ increase & $-0.20(-0.29$ to -0.11$)$ & $<0.001$ \\
\hline
\end{tabular}

AMS, acute mountain sickness; HR, heart rate; ICP, intracranial pressure; ONSD, optic nerve sheath diameter; Ref, reference value.

*Allowing for repeated measures in the same individual, and adjusted for age, sex, right and left eye, assessment of scan quality, whether the ocular lens was visible in the scan, and for three people who had returned to 6400 metres after an earlier climb. $\dagger$ Numbers in parentheses in first column are mean, range.

earlier instruments; Ophthalmic Technologies, Canada) resulted in images of superior quality, allowing the observer to identify the optic nerve sheath more readily. Although the statistical power of the findings was improved by taking repeat measures in the same subjects, the study involved only 13 people, thus larger numbers are needed to verify the apparent linear associations observed.

Our results are in keeping with studies on both large and small animals, which have shown raised ICP at simulated altitudes, ${ }^{4-6}$ but contrast with a recent study that used CSFp as a
Figure 5 Ophthalmic B-scan ultrasound images at sea level (optic nerve sheath diameter (ONSD), $4086 \mathrm{~mm}$ ) and $5200 \mathrm{~mm}$ (ONSD, $6.57 \mathrm{~mm}$ ) in a subject who developed high-altitude cerebral oedema on arrival at advanced base camp (6400 m).
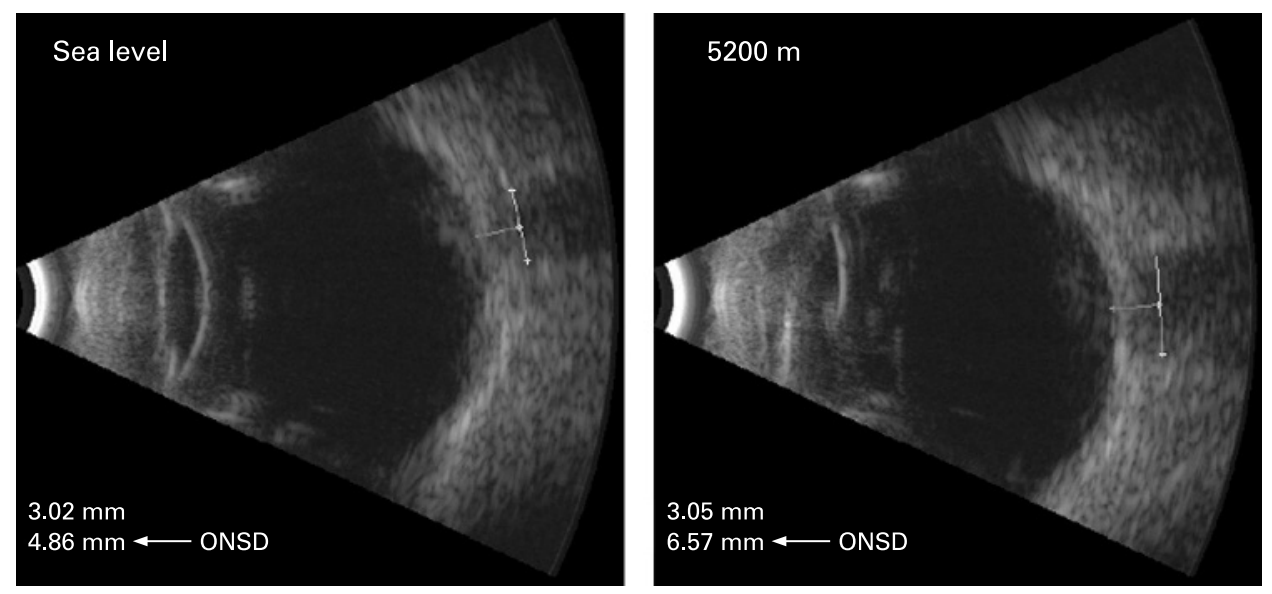
proxy for ICP and failed to show CSF pressure increases at simulated altitudes. ${ }^{9}$ The reason for this discrepancy may be because subjects were exposed to relatively short periods of normobaric hypoxia, and were motionless in a supine position, a posture associated with lower levels of ICP. Furthermore, no challenge was given to assess CSFp reserve capacity.

In addition to the associations found of ONSD with altitude and AMS, we also found strong associations between ONSD and resting heart rate, and between ONSD and oxygen saturations. This is not surprising as heart rate and oxygen saturation are strongly dependent on the partial pressure of oxygen at any given altitude. ${ }^{23}$ Interestingly, however, when all parameters were compared together, the strongest association was found between heart rate and ONSD. Heart rate has been shown to correlate with severity of $\mathrm{AMS},{ }^{24}$ and several studies have suggested that sympathetic activation is important in the pathophysiology of AMS. ${ }^{25-27}$ The strong relationship between heart rate and ONSD may reflect this, and higher heart rates may offer a more objective measure of AMS severity.

Although our findings suggest that ICP is important in the pathophysiology of AMS, we are unable to establish causality. ICP may represent only one factor in a multifactorial process. It is of interest that at $6400 \mathrm{~m}$, where subjects had spent a much longer time at altitude, we saw a further increase in average ONSD, whereas AMS symptoms decreased (fig 4). It is possible that, after extended periods at altitude, people develop a degree of tolerance to consistently raised ICP. The reason for individual susceptibility to AMS has been a long-standing conundrum in high-altitude physiology. It has been showed that the brain swells during periods of sustained hypobaric hypoxia; however, the degree of swelling does not correlate with AMS severity. ${ }^{28-30}$ Ross hypothesised that people with a smaller intracranial and intraspinal CSF capacity would be less able to buffer brain swelling, and would subsequently develop AMS due to raised ICP. ${ }^{31}$ Supporting this hypothesis are several reports of people with impaired cerebrospinal buffering capacity due to spaceoccupying lesions, who have developed symptoms of raised ICP when exposed either to altitude ${ }^{32} 33$ or to the hypobaric hypoxia of commercial aircraft. ${ }^{34}$ Conversely, there is a lower incidence of AMS in older people, ${ }^{35}$ who have been shown to have a greater CSF-to-brain volume. ${ }^{36}$ In our study, the three subjects with ONSD $>6 \mathrm{~mm}$ at $5200 \mathrm{~m}$ all had increases in the region of $1.5 \mathrm{~mm}$ compared with sea level. These three subjects (all male) may have a reduced ratio of CSF-to-brain volume, thus predisposing them to raised ICP on ascent to altitude. Although we are not able to quantify their ICP from ONSD measurements, Hansen's paper ${ }^{11}$ gives us an indication that ONSD increases of this magnitude may represent ICP increases $>20 \mathrm{~mm} \mathrm{Hg}$. Although speculative, if we are seeing ICP increases of this magnitude at $5200 \mathrm{~m}$, and ICP continues to increase on ascent to higher altitudes, it is likely that ICP plays an important role in the significant mortality we see in mountaineers climbing mountains such as Mount Everest $(8850 \mathrm{~m}){ }^{37}{ }^{38}$

We have shown that ONSD measurement is a simple and safe technique to use in the difficult environment of a high-altitude expedition to Mount Everest. Although measures of ONSD were not predictive of AMS higher on the Mountain, ONSD showed a strong, graded association with altitude, AMS score, resting heart rate and oxygen saturations. Further studies with larger numbers examining ONSD in the clinical setting and at altitude are needed. Repeating our study under controlled conditions in a larger cohort, with the addition of manoeuvres to change ICP such as hyperventilation, change in posture and

\section{What is already known on this topic}

- Raised intracranial pressure (ICP) has been suggested as a possible cause for acute mountain sickness (AMS), but the association has been difficult to study because of the invasive nature of ICP measurement.

- Animal studies have shown increases in ICP at simulated altitudes, but limited human studies have given conflicting results.

- B-scan ultrasound measurement of optic nerve sheath diameter (ONSD) has been shown to correlate with ICP and can be used to study ICP at high altitude.

\section{What this study adds}

- We were able to successfully measure ONSD in climbers from sea level to $6400 \mathrm{~m}$.

- ONSD increases significantly at high altitude and this increase is associated with symptoms of acute mountain sickness (AMS).

- Our study suggests that intracranial pressure may play an important role in the pathophysiology of AMS.

increased levels of carbon dioxide (to increase cerebral blood volume) would help to elucidate the relationship between ICP at altitude and AMS. Studies specifically examining the effect of exercise and therapeutic interventions (such as dexamethasone or oxygen) on ONSD would also be of considerable interest.

Our findings, even in this small study group, are robust and significant, and given the evidence of the linkage between ONSD and ICP, we suggest that ICP is raised with increasing altitude and that this increase is associated with more severe symptoms of AMS. B-scan ultrasonography of the optic nerve sheath offers a new non-invasive technique for measuring ICP, which has many possible applications both at sea level and high altitude.

Acknowledgements: We are grateful to the Everestmax team for volunteering to take part in the research project. We also grateful to OTI Inc for providing the ultrasound equipment, and to the Carnegie Trust for the Universities of Scotland. All authors contributed substantially to the conception and design of this study. AIS and CGO obtained clinical measures, including ultrasound scans which were measured by DSM. AIS drafted the paper and CGO carried out statistical analysis. The paper was critically appraised by all authors for intellectual content; AIS and CGO will act as guarantors. The guarantors accept full responsibility for the integrity of the work as a whole. All authors had access to the data, and approved the final version to be published.

Funding: A small project grant was received from the Carnegie Trust for the Universities of Scotland. AIS is funded by a Wellcome Research Training Fellowship. The authors are independent from the funders.

Competing interests: None.

Ethics approval: This study was approved by the Oxford Tropical Research Ethics Committee (Ref: 015-06 "Investigation of Intracranial Pressure at High Altitude").

\section{REFERENCES}

1. Barry PW, Pollard AJ. Altitude illness. BMJ 2003;326:915-19.

2. Hackett PH, Roach RC. High-altitude illness. N Engl J Med 2001;345:107-14.

3. Singh I, Khanna PK, Srivastava MC, et al. Acute mountain sickness. N Engl J Med 1969:280:175-84.

4. Senay LC Jr, Tolbert DL. Effect of arginine vasopressin, acetazolamide, and angiotensin II on CSF pressure at simulated altitude. Aviat Space Environ Med 1984;55:370-6

5. Yang YB, Sun B, Yang Z, et al. Effects of acute hypoxia on intracranial dynamics in unanesthetized goats. J Appl Physiol 1993;74:2067-71. 
6. Yang SP, Bergo GW, Krasney E, et al. Cerebral pressure-flow and metabolic responses to sustained hypoxia: effect of C02. J Appl Physiol 1994;76:303-13.

7. Lenfeldt $\mathbf{N}$, Koskinen LO, Bergenheim AT, et al. CSF pressure assessed by lumbar puncture agrees with intracranial pressure. Neurology 2007:68:155-8.

8. Houston CS, Dickinson J. Cerebral form of high-altitude illness. Lancet 1975;2:75861.

9. Bailey DM, Roukens $\mathrm{R}$, Knauth $\mathrm{M}$, et al. Free radical-mediated damage to barrier function is not associated with altered brain morphology in high-altitude headache. J Cereb Blood Flow Metab 2006;26:99-111.

10. Hansen HC, Helmke K. The subarachnoid space surrounding the optic nerves. An ultrasound study of the optic nerve sheath. Surg Radiol Anat 1996;18:323-8.

11. Hansen HC, Helmke K. Validation of the optic nerve sheath response to changing cerebrospinal fluid pressure: ultrasound findings during intrathecal infusion tests. J Neurosurg 1997;87:34-40.

12. Liu D, Kahn M. Measurement and relationship of subarachnoid pressure of the optic nerve to intracranial pressures in fresh cadavers. Am J Ophthalmol 1993;116:54856.

13. Gangemi M, Cennamo G, Maiuri F, et al. Echographic measurement of the optic nerve in patients with intracranial hypertension. Neurochirurgia (Stuttg) 1987;30:535 .

14. Helmke K, Burdelski M, Hansen HC. Detection and monitoring of intracranial pressure dysregulation in liver failure by ultrasound. Transplantation 2000;70:392-5.

15. Kimberly H, Shah S, Marill K, et al. Correlation of optic nerve sheath diameter with direct measurement of intracranial pressure. Acad Emerg Med 2007;14(Suppl.):S98.

16. Newman WD, Hollman AS, Dutton GN, et al. Measurement of optic nerve sheath diameter by ultrasound: a means of detecting acute raised intracranial pressure in hydrocephalus. Br J Ophthalmol 2002;86:1109-13.

17. Tayal VS, Neulander M, Norton HJ, et al. Emergency department sonographic measurement of optic nerve sheath diameter to detect findings of increased intracranial pressure in adult head injury patients. Ann Emerg Med 2007:49:508-14.

18. Blaivas M, Theodoro D, Sierzenski PR. Elevated intracranial pressure detected by bedside emergency ultrasonography of the optic nerve sheath. Acad Emerg Med 2003; 10:376-81.

19. Helmke K, Hansen HC. Fundamentals of transorbital sonographic evaluation of optic nerve sheath expansion under intracranial hypertension II. Patient study. Pediatr Radiol 1996;26:706-10.

20. Ballantyne SA, O'Neill G, Hamilton R, et al. Observer variation in the sonographic measurement of optic nerve sheath diameter in normal adults. Eur $\mathrm{J}$ Ultrasound 2002;15:145-9.
21. Roach RC, Bartsch P, Oelz O, et al. Hypoxia and molecular medicine: The Lake Louise acute mountain sickness scoring system. Burlington, VT: Queen City Press, 1993.

22. Geeraerts T, Launey $Y$, Martin L, et al. Ultrasonography of the optic nerve sheath may be useful for detecting raised intracranial pressure after severe brain injury. Intensive Care Med 2007;33:1704-11.

23. Reeves JT, Groves BM, Sutton JR, et al. Operation Everest II: preservation of cardiac function at extreme altitude. J Appl Physiol 1987;63:531-9.

24. O'Connor T, Dubowitz G, Bickler PE. Pulse oximetry in the diagnosis of acute mountain sickness. High Alt Med Biol 2004;5:341-8.

25. Hoon RS, Sharma SC, Balasubramanian V, et al. Urinary catecholamine excretion on acute induction to high altitide (3,658 m). J Appl Physiol 1976;41:631-3.

26. Bartsch P, Maggiorini M, Schobersberger W, et al. Enhanced exercise-induced rise of aldosterone and vasopressin preceding mountain sickness. J Appl Physiol 1991;71:136-43.

27. Bartsch $\mathbf{P}$, Shaw $S$, Franciolli $M$, et al. Atrial natriuretic peptide in acute mountain sickness. J Appl Physiol 1988;65:1929-37.

28. Kallenberg K, Bailey DM, Christ $\mathrm{S}$, et al. Magnetic resonance imaging evidence of cytotoxic cerebral edema in acute mountain sickness. J Cereb Blood Flow Metab 2007:27:1064-71.

29. Fischer R, Vollmar C, Thiere $\mathbf{M}$, et al. No evidence of cerebral oedema in severe acute mountain sickness. Cephalalgia 2004;24:66-71.

30. Morocz IA, Zientara GP, Gudbjartsson H, et al. Volumetric quantification of brain swelling after hypobaric hypoxia exposure. Exp Neurol 2001;168:96-104.

31. Ross RT. The random nature of cerebral mountain sickness. Lancet 1985:1:990-1.

32. Shlim DR, Nepal K, Meijer HJ. Suddenly symptomatic brain tumors at altitude. Ann Emerg Med 1991;20:315-16.

33. Hackett PH. Subarachnoid cyst and ascent to high altitude - a problem? High Alt Med Biol 2000;1:337-9.

34. Muhm JM, Rock PB, McMullin DL, et al. Effect of aircraft-cabin altitude on passenger discomfort. N Engl J Med 2007;357:18-27.

35. Wagner DR, Fargo JD, Parker D, et al. Variables contributing to acute mountain sickness on the summit of Mt Whitney. Wilderness Environ Med 2006;17:221-8.

36. Ikram MA, Vrooman HA, Vernooij MW, et al. Brain tissue volumes in the general elderly population The Rotterdam Scan Study. Neurobiol Aging Published Online First 4 September 2007. doi: 10.1016/j.neurobiolaging.2007.07.009.

37. Huey RB, Eguskitza X. Limits to human performance: elevated risks on high mountains. J Exp Biol 2001;204(Pt 18):3115-19.

38. Sutherland AI. Why are so many people dying on Everest? BMJ 2006;333:452.

\section{Call for papers: BMJ theme issue on sport and exercise medicine}

The $B M J$ is planning a theme issue on sport and exercise medicine in July 2008. If you would like your original research to be considered for the issue, please send it to our online editorial office at http:// submit.bmj.com by Tuesday 8 April 2008. We are particularly interested in clinical research and will give priority to reports of randomised controlled trials or other original quantitative research that will help doctors and patients to make better decisions. We are also interested in translational research that is relevant to clinical decision making.

Our resources for authors on bmj.com and an editorial provide answers to common questions about submitting research to the BMJ. All submissions should follow the standard requirements for BMJ articles and are subject to standard editorial and peer review processes.

For additional advice on possible submissions for this theme issue, please email Domhnall MacAuley at dmacauley@bmj.com 